\title{
SOBRE LA RELACIÓN ENTRE TEXTO E IMAGEN. UNA APROXIMACIÓN SEMIO-FENOMENOLÓGICA A FIN DE ETAPA, DE JULIO CORTÁZAR
}

\author{
ON THE RELATIONSHIP BETWEEN TEXT AND IMAGE. A SEMIO- \\ PHENOMENOLOGICAL APPROACH TO JULIO CORTAZAR'S FIN DE ETAPA
}

\author{
Carlos Andrés PÉREZ RAMÍREZ \\ Universidad Jorge Tadeo Lozano (Colombia) \\ carlos.perez@utadeo.edu.co
}

\begin{abstract}
Resumen: en este trabajo abordo el problema semiótico de la relación entre texto escrito e imagen visual desde una perspectiva fenomenológica. Primero trazo los elementos comunes a los dos tipos de signo y luego especifico algunas de sus diferencias. Teniendo en cuenta lo anterior analizo el cuento de Cortázar Fin de etapa y trato de describir, dentro de un marco fenomenológico, el giro fantástico que éste propone.

Palabras clave: Fenomenología. Signo visual. J. Cortázar. Husserl.

Abstract: in this paper, I address the semiotic question concerning the relationship between written text and visual image, from a phenomenological point of view. First, I identify the phenomenological structure shared by both kinds of sign, and then proceed to specify some of the differences between them. Then, I analyze Julio Cortazar's Fin de etapa, trying to describe and capture, within a phenomenological framework, the fantastic turn it proposes.
\end{abstract}

Key Words: Phenomenology. Visual sign. J. Cortázar. Husserl. 


\section{INTRODUCCIÓN}

Según cuenta Julio Cortázar en su conversación con Omar Prego (1997), la escritura de Fin de Etapa surge a raíz de la solicitud hecha por el pintor Antoni Taulé para prologar una de sus exposiciones. Las descripciones que hace Cortázar de las pinturas de Taulé a lo largo del relato dejan ver con claridad de qué tipo de obra se trata: pinturas hiperrealistas que motivan en la mente del espectador cierta sensación de soledad y de melancolía. Quien tenga la posibilidad de acceder a las reproducciones visuales de las pinturas ${ }^{1}$ seguramente quedará expuesto a un intercambio de sentido entre lo visual y lo literario que amplía el horizonte interpretativo tanto del cuento como de las pinturas y que, para alguien interesado en semiótica, obliga a volver de nuevo sobre el problema de la relación entre imagen y palabra.

En el cuento, Cortázar invita a ver las pinturas de dos maneras diferentes: en la primera parte, se entienden como cuadros que representan diferentes escenas; en la segunda, se entienden como espacios recorridos por Diana, la protagonista del relato. El giro fantástico que organiza al cuento la sitúa primero como espectadora de unas pinturas en la sala de un museo, para volverla luego parte integral de esas pinturas.

El análisis del giro propuesto por Cortázar ha sido el tema de algunos trabajos académicos (Alazraki, 1994; Ruiz, 1996; Haghroosta, 2011) interesados sobre todo en mostrar las estrategias narrativas de las que se vale el autor para introducir el problema de la soledad y de la oposición entre lo irreal y lo real, y de su solución literaria, que se construye cuando el relato se desliza hacia el terreno de lo fantástico. Sin embargo, el tema de la pintura y el contrapunteo entre lo visual y lo verbal se toca solo de manera tangencial ${ }^{2}$. El presente texto pretende llenar ese vacío, pero busca también adelantar algunas ideas sobre el problema general de la relación entre imagen y texto.

Se trata de una discusión que en semiótica tiene una larga trayectoria. Para la tradición estructuralista, la relación entre texto e imagen se ha entendido al menos de tres maneras: o bien sosteniendo la primacía de lo lingüístico sobre lo visual (Barthes, 2009), esto es, reservando al dominio de la lengua todo acto genuino de dación de sentido y situando

1 Disponibles en la página del pintor: $h t t p: / / w w w . a n t o n i t a u l e . c o m /[01 / 12 / 2016]$

2 Ruiz es quizás la única que se aproxima al cuento asumiendo como tema central el problema estético que plantean las pinturas. Sin embargo, su análisis termina centrándose en la manera como se construye narrativamente el personaje de Diana: la pasividad del espacio y del entorno al inicio del cuento, su actitud inicial frente a las pinturas, el juego de las simetrías que se introduce hacia la mitad del relato y la apropiación final del personaje por las pinturas, que conducen a su muerte simbólica. Solo hacia el final se presentan algunas ideas sobre la pintura, insistiendo en un par de nociones claves de la propuesta hiperrealista (la pintura como apropiación de la realidad y la oposición entre representar y presentar). Sin embargo, tales apreciaciones quedan apenas enunciadas y nunca se hace referencia directa a las pinturas de Taulé. 
a las imágenes en una posición subsidiaria en relación con lo verbal; o bien mostrando que las diferencias de superficie se resuelven en la estructura de fondo, en la medida en que tanto las imágenes como el texto escrito se organizan siguiendo un mismo recorrido generativo (Floch, 1993); o bien determinando las condiciones de significación propias de cada sistema de signos (los lingüísticos y los visuales), entendiendo los casos de vinculación intertextual como ejemplos de discursos pluricódicos (Klinkenberg, 2006). Por su parte, para la tradición peirceana el problema de la relación texto e imagen se entendería, en la versión de Eco defendida en el Tratado de Semiótica General (2005), como una cadena de interpretantes.

El enfoque que voy a seguir en este texto no es, sin embargo, ni el estructuralista ni el peirceano, sino uno enmarcado en el giro cognitivo que ha dado la semiótica desde ya algunos años, esto es, en el esfuerzo por determinar el lugar que tiene el estudio de los procesos y de las estructuras mentales en la comprensión de los procesos de construcción de sentido. Desde luego, como pasa con todo lo nuevo, esta sacudida está todavía por decantarse. De entrada, pretender resolver la pregunta por el sentido con base en hallazgos neurológicos sobre el funcionamiento del cerebro (Bergen, 2012) supone un error categorial y un reduccionismo científico que antes que resolver el problema, lo desdibuja y lo aplaza (Pérez, 2016). Por eso, la consolidación de un marco metodológico semióticamente fructífero, así como la definición de los conceptos claves que deben apuntalar este nuevo horizonte teórico, son todavía tareas incipientes que están esperando ser resueltas de manera más concluyente. Algunos intentos interesantes se pueden encontrar en la apropiación semiótica de algunas de las tesis de la lingüística cognitiva poschomskiana (Brandt, P. 2004; Brandt, L., 2013); también en la reformulación, en clave contemporánea, de algunas ideas de la semiótica peirceana (Stjernfeld, 2014); y finalmente en la apropiación semiótica de la fenomenología de Husserl (Sonesson, 2012; Zlatev, 2010; Bundgaard, 2015).

Este artículo se ubica en esta última tendencia. La decisión se debe, principalmente, al carácter sintético de la propuesta fenomenológica, que sirve para conciliar las tensiones que hay entre la devoción estructuralista por texto y el culto peirceano por los signos y la lógica. Y se explica, también, por el tipo de objetivo que anima al presente texto, esto es, el de dar cuenta del giro que propone Cortázar en relación con las pinturas de Toulé. En efecto, espero mostrar al final de mi texto la relevancia que tienen algunas de las herramientas de la fenomenología en la comprensión de los procesos de dación de sentido involucrados en la interpretación del cuento y de las pinturas.

Con tal propósito en mente, voy a retomar y desarrollar, primero, algunas de las definiciones básicas adelantadas por Husserl sobre la noción de signo. Luego voy a presentar algunas ideas específicas sobre los signos lingüísticos, combinando sus tesis iniciales con algunas de sus ideas tardías. Después voy a presentar sus ideas sobre los 
signos visuales. Y finalmente presentaré con algo de detalle el cuento de Cortázar para hacer un análisis de la relación entre la narración y las pinturas de Taulé.

\section{TEXTO E IMAGEN EN EL CRUCE ENTRE LA SEMIÓTICA Y LA FENOMENOLOGÍA}

En este numeral voy a presentar algunas ideas generales sobre la fenomenología para dar paso a la presentación de la propuesta de Husserl sobre los signos verbales y los signos visuales.

\subsection{IDEAS GENERALES}

La fenomenología procura hacer una descripción rigurosa de la experiencia consciente con el propósito de resolver el problema filosófico de la intencionalidad, esto es, el hecho de que nuestros estados conscientes son siempre dirigidos a algo. Siguiendo la formulación común, decimos con la fenomenología que toda consciencia es consciencia de algo, y todo objeto de experiencia es objeto para una consciencia. De ahí que se distinga entre el acto intencional del objeto intencional. Por ejemplo, cuando observamos una mesa, debemos distinguir entre el acto de ver la mesa y la mesa en tanto que es vista; cuando la recordamos, distinguimos entre el acto de recordarla y la mesa en tanto que es recordada; cuando juzgamos que la mesa es azul, diferenciamos el acto judicativo del estado de cosas que se afirma, etc. El trabajo de la fenomenología consiste en describir y establecer la estructura de esa relación.

Husserl (1999) entiende que el modo más básico de la experiencia humana es el de la intuición originaria de un objeto, esto es, la presencia directa de éste a la consciencia en un acto de percepción -su presencia sensible-, y diferencia este modo de otros, que denomina intenciones vacías, en los que el objeto se da, pero no de manera inmediata sino mediada. En este tipo de actos el objeto no se presenta de manera directa, sino que se presentifica, esto es, se hace presente a la consciencia solo de manera mediada. Tal es, por ejemplo, el caso de los signos: cuando estamos ante un signo, un objeto se presentifica mediado por la expresión sígnica, y de lo que se ocuparía la fenomenología sería entonces de capturar la experiencia propia de este acto interpretativo, esto es, de establecer las condiciones experienciales a partir de las cuales una expresión sígnica es precisamente eso y no otra cosa.

No se trata, simplemente, de un esfuerzo por establecer introspectivamente aquello en lo que consiste una experiencia, sino de capturar, siguiendo una metodología estricta, los rasgos estructurales de esa experiencia. Volviendo sobre la intención sígnica, Husserl (1999) entiende que se trata de un acto interpretativo constituido por un ítem presente 
que presentifica un objeto diferente. Algo que recuerda al aliquid stat pro aliquo, solo que en este caso no se trata de establecer las condiciones lógicas que definirían un signo, sino sus condiciones fenomenológicas, esto es, qué hace del signo un objeto experiencial y cómo se constituye.

La idea central, digámoslo de nuevo, es que, fenomenológicamente, un signo llega a significar únicamente en virtud de una intención significativa que lo anima. Significar, si se quiere, es una acción llevada a cabo por el sujeto, no por el signo, y para comprender dicho acto es preciso hacer algunas distinciones fenomenológicas. En las Investigaciones lógicas Husserl se expresa en los siguientes términos:

¿Qué es, en general, ese más que tiene la expresión entendida (pero funcionando de un modo meramente simbólico) sobre el sonido articulado vacío de pensamiento? ¿En qué consiste la diferencia entre intuir simplemente un objeto concreto A y apercibirlo como "representante" de "un A cualquiera"? En estos casos y otros innumerables semejantes, la modificación radica en los caracteres de acto (Husserl, 1999: 502).

Se habla de apresentación cuando dos ítems se relacionan en la experiencia: uno presente y el otro ausente. Así, por ejemplo, cuando veo mi mano, la parte visible está presente ante mis ojos y la observo directamente, mientras que la parte oculta es una apresentación. Mi acto perceptivo no se dirige a los perfiles presentes sino a los objetos en su unidad (para ponerlo de manera escueta, si me preguntan qué estoy viendo respondo "una mano"y no "el perfil de una mano"), pero en relación con el perfil presente los perfiles ocultos son, precisamente, apresentaciones. Lo mismo sucede en el caso de la experiencia de otros seres humanos: los demás aparecen en mi experiencia como seres animados, pero los apercibo como el cuerpo animado de otro ser humano. Así, la vida mental de ese Otro cuyo cuerpo percibo es una apresentación. De manera simple, para evitar confusiones: el cuerpo del otro, en tanto que objeto perceptivo, apresenta los perfiles ocultos a la vista, mientras que el cuerpo del otro, en tanto que sujeto o cuerpo animado, apresenta su vida mental.

Ahora bien, sería un error considerar el perfil como el signo de la parte oculta del objeto, en la medida en que, por lo general, cuando percibo un objeto la atención está dirigida a la totalidad de éste y no a sus perfiles ocultos. En el caso de los signos, como acertadamente ha insistido G. Sonesson (2012), tenemos una apresentación en la que la atención temática está dirigida al ítem ausente. Cuando vemos, por ejemplo, una columna de humo y la interpretamos como índice del fuego, el fuego no hace parte de nuestro campo perceptivo, pero hacia él está dirigida la atención del acto. También pasa lo mismo cuando leemos una novela, interesados como estamos en lo que se narra y no en 
los rasgos tipográficos de la edición (a menos que se trate de una tipografía especial que llame mucho mi atención, en cuyo caso la palabra escrita se convertiría en el objeto de mi acto). De nuevo, es por eso Husserl llama a los actos interpretativos presentificaciones, en el sentido en que el objeto no está dado de manera directa, sino que se hace presente a la experiencia por la mediación de una construcción sígnica.

\subsection{EL LENGUAJE Y LA LECTURA}

En el numeral anterior señaléalgunos aspectosgeneralesque, desdelafenomenología, caracterizan a los signos en general. No obstante, no es difícil advertir que hay más elementos en juego si lo que se busca es hacer una caracterización fenomenológica completa de una obra literaria. Es cierto que Husserl nunca tuvo dentro de su horizonte teórico el análisis de este tipo de objetos, no obstante, su propuesta fenomenológica es lo suficientemente rica como para identificar algunos aspectos relevantes que servirán de punto de comparación ${ }^{3}$.

\subsubsection{La materia fónica}

En la Introducción a Lógica formal y Lógica trascendental, Husserl (2009) retoma algunos problemas relacionados con el lenguaje y adelanta lo que se conoce como la tesis de la idealidad del lenguaje: a pesar de ser una realización concreta, cada obra literaria existe como una idealidad. Cada ejemplar de, digamos, Cien años de soledad, es un ejemplar de una misma obra literaria, así como la Quinta sinfonía de Beethoven es una sola, aunque la toquen diferentes orquestas en diferentes lugares. Así, aunque en la lectura puntual se resuelve la especificidad de la obra -su carácter concreto-, la organización del material fónico de la obra, representado visualmente por medio de la escritura, existe como una idealidad. En otras palabras, en tanto que materia fónica, la obra literaria se desenvuelve en su manifestación sensible concreta, esto es, en las cualidades propias de su realización, pero se trata de la realización de un tipo, de una idealidad, según lo que acabamos de decir: cada obra literaria es una única obra. El punto importante es que independientemente de su significado, las palabras y las frases tienen una dimensión sonora que de suyo impone un ritmo y un tempo propio, y la manera específica como se vinculan en el curso temporal de la experiencia admite un análisis fenomenológico encaminado a dilucidar los rasgos estéticos de dicha materia fónica.

Las reglas que rigen la organización de las cualidades sensibles (que Husserl llama materia hylética) son el tema central en buena parte de los Análisis sobre la síntesis pasiva

3 Una caracterización completa de la obra literaria, inspirada en la fenomenología de Husserl, se encuentra en el extenso y maravilloso estudio llevado a cabo por Roman Ingarden (1998) en La obra de arte literaria. 
(Husserl, 2001). La idea central es que la materia hylética está dispuesta temporalmente y se organiza de acuerdo a la estructura fenomenológica de la experiencia temporal. Para Husserl, toda experiencia presente se compone de tres fases: retención, impresión primordial y protención. La retención es la huella que deja en la consciencia lo recién acontecido: cuando escuchamos una pieza musical, cada sonido que escuchamos se pierde en el pasado apenas aparece, pero su presencia se mantiene, precisamente, en la protención. El sonido deja de ser, pero no desaparece sin más. Por eso no escuchamos las notas una detrás de otra, sin ninguna conexión entre sí, sino un flujo sonoro continuo que contiene, incluso, las pausas y los silencios. La protención, por su parte, es la expectativa que define toda experiencia presente: vivimos el mundo temporalmente volcados hacia adelante. Toda experiencia presente va de la mano de una expectativa de lo por venir. Si escuchamos una serie de notas musicales, el sonido de la nota que todavía no hemos escuchado pero que anticipamos experiencialmente lo vivimos en el modo de la protención. De ahí que la consciencia del tiempo se deba entender como una síntesis de los diferentes momentos involucrados en la experiencia temporal: cuando escucho una sinfonía, cada instante está vinculado con el que acaba de pasar y con el que se anuncia, y lo hace siguiendo unas reglas de asociación pasiva identificadas por Husserl en sus Análisis y que él clasifica en dos grupos: síntesis de homogeneidad (similaridad, uniformidad, fusión) y síntesis de heterogeneidad (contraste, discreción, prominencia) (Husserl, 2001: 174).

Lo mismo sucede con las palabras: independientemente de su significado, tejen un nivel básico temporal en el que el mismo sonido de lo leído cae en la protención y se lanza hacia la protención. Así, el simple hábito sonoro vinculado con la lengua define un horizonte sensible que es lo que hace inteligible hablar del ritmo de las palabras y de su tempo. Miremos, por ejemplo, el siguiente fragmento del cuento que nos ocupará en la cuarta parte, que he dividido en dos partes para facilitar el comentario posterior4:

[1] Sentía en la piel una frescura de sombra, algunos parroquianos jugaban a las cartas, dos chicos con un perro, una vieja en el puesto de periódicos, todo como fuera del tiempo, estirándose en la calina del verano. [2] Como fuera del tiempo, lo había pensado mirando la mano de uno de los jugadores que mantenía largamente la carta en el aire antes de dejarla caer en la mesa con un latigazo de triunfo (Cortázar, 1996: 426).

Además de la estupenda descripción de la escena, el fragmento es un acierto literario por la musicalidad de su escritura. Primero algunas frases cortas, separadas por comas,

4 Los números entre corchetes que hay en la cita los introduzco yo. 
le dan un tempo pausado al inicio de la cita. Luego, en la siguiente oración, Cortázar repite las palabras "como fuera del tiempo", imprimiendo ritmo a la narración y dando paso a una frase extensa que contrasta con las de la primera mitad; una frase que se estira largamente -como el movimiento del jugador de naipe-casi que frenando la secuencia de pausas presente en la primera frase.

Lo que estoy haciendo es, desde luego, una descripción informal. Me interesa nada más señalar que no tendría ningún sentido hablar de ritmo si no estuviera en la retención la frase "como fuera del tiempo" cuando leemos el inicio de la segunda oración, como tampoco tendría sentido hablar de tempo si las frases separadas que configuran la primera oración no fueran cayendo en la retención una vez se van leyendo. En efecto, una cosa es leer la oración dos después de haber leído la primera, y otra muy diferente si no, pues las pausas no estarían en la retención y el efecto de duración no sería el mismo.

\subsubsection{Los significados y el objeto}

La idealidad de las expresiones lingüísticas va de la mano de una segunda idealidad: la de los significados. La materia fónica está organizada en unidades cuyas combinaciones configuran palabras y oraciones con sentido. Una persona puede leer un texto en un idioma que desconoce si sabe cómo se pronuncian las palabras, pero solo lee si, además de saber cómo se pronuncian, sabe lo que dichas palabras significan.

Dependiendo de la teoría semántica que se siga, el significado de una expresión lingüística se puede especificar de forma lógica -como lo ha intentado la filosofía analítica-, o estableciendo su lugar en campos semánticos -como lo intentó la escuela estructuralista- o situando el significado en la red enciclopédica del usuario (Eco, 2005). De nuevo, el debate en este punto tiene tanto de largo como de ancho. El punto distintivo de la teoría de Husserl es que el significado de las palabras se debe entender dentro del marco propio de una teoría fenomenológica que se ocupa, fundamentalmente, del problema de la intencionalidad.

Cuando leo que"tal vez se detuvo ahí porque el sol ya estaba alto y el mecánico placer de manejar el auto en las primeras horas de la mañana cedía paso a la modorra, a la sed" (Cortázar, 1996: 426), que es como Cortázar da inicio a Fin de Etapa, las palabras dan lugar a un acto interpretativo mediante el cual dirijo mi consciencia a la situación descrita en la frase. Pero lo hago mediado por el contenido de las palabras: el objeto intencional se presentifica según el modo establecido por el significado del acto significativo. Nada diferente a lo que han planteado en el campo de la lingüística cognitiva autores como $R$. Langaker (2008) y L. Talmy (2003). Por ejemplo, dice Langacker5:

5 Todas las citas de Langacker son traducciones mías. 
Un significado consiste en un contenido conceptual y una manera particular de construirlo. El término "construcción" [construal] hace referencia a nuestra habilidad manifiesta para concebir y retratar la misma situación de maneras alternativas (Langacker, 2008: 43).

Langacker ilustra su punto con el ejemplo de un vaso que contiene una cantidad que agua que ocupa solamente la mitad de su volumen:

A nivel conceptual, presumiblemente somos capaces de evocar este contenido de una manera neutral. Pero tan pronto como lo codificamos lingüísticamente, imponemosnecesariamente una determinada construcción. [...] El contraste semántico descansa en lo que las expresiones designan (o a lo que refieren) en relación con la situación concebida: (1) el vaso con agua en su interior designa al contenedor; (2) el agua en el vaso designa el líquido que éste contiene; (3) el vaso medio lleno designa la relación en la que el volumen que ocupa el líquido está solamente hasta la mitad de su volumen potencial; y (4) El vaso está medio vacío designa la relación en la que el volumen que ocupa el vacío está solamente hasta la mitad de su volumen potencial (Langacker, 2008: 43).

El hecho de optar por una de las cuatro opciones implica, por un lado, llamar la atención sobre uno de los rasgos de la escena representada, y por el otro, dejar de lado otros rasgos de la misma escena. La escena existe independientemente de la construcción lingüística mediante la cual dirigimos nuestra consciencia hacia ella; no obstante, la manera como se presentifica dicha escena sí está determinada por el tipo de construcción que escojamos. Bundgaard (2010) complementa esta idea y señala cómo, en el caso de las obras literarias, el modo de presentación se organiza a lo largo de tres ejes: (1) la focalización, que es el énfasis que se hace -o no- en la situación de los personajes con respecto a los hechos narrados, (2) el modo de narración, que es el tipo de relación que guarda el narrador con el objeto narrado, y (3) la granularidad, que es el nivel de detalle con el que una narración presenta su objeto (focalización y granularidad serán importantes cuando abordemos el cuento de Cortázar en el numeral 4.2.1).

Por ejemplo, en el inicio del cuento encontramos (1) una narración que focaliza la situación vivida de la protagonista y no la situación objetiva, (2) un modo de narración en el que el narrador no está vinculado directamente con lo que se narra, y (3) una descripción más bien gruesa, en la medida en que no da muchos detalles sobre lo que está pasando. Por ejemplo, no se dice nada sobre el lugar de origen ni sobre el lugar de destino del viaje que realiza Diana, pero sí que se encuentra en medio de dicho trayecto 
(se detuvo ahí). También se llama la atención sobre su estado corporal (la modorra, la sed) y sobre el momento del día en el que decide tomar un desvío hacia el pueblo (el sol ya estaba alto). Así, la situación representada supone un mundo más amplio, un trasfondo, o en términos fenomenológicos, un horizonte que no puede ser representado explícitamente por el conjunto de palabras que componen el cuento. Veamos.

\subsubsection{El objeto y el trasfondo}

En este numeral quiero decir algo sobre los puntos ciegos que deja un relato ${ }^{6}$ y que el lector de una obra literaria está en la capacidad de recrear. Desde el punto de vista del acto interpretativo, estos puntos ciegos no hacen parte del acto en cuanto tal -que está siempre dirigido a un objeto intencional- sino que configuran las condiciones que lo hacen posible. El lector no puede dirigir su consciencia a todo lo que en el libro no se narra, pues esto volvería eterna la lectura de cualquier obra literaria. Sin embargo, el acto interpretativo supone lo que Clark (1996) ha llamado terreno común, y que en fenomenología se entendería de la mano de la oposición entre el mundo común -el hogar, entendido aquí en un sentido amplio como el mundo cultural compartido- y el mundo ajeno (es decir, de quienes no hacen parte de mi esfera cultural).

Husserl intentó comprender la experiencia de lo intersubjetivo-cultural en los análisis generativos, en los que se ocupó de ese carácter distintivo de la experiencia vinculado con la habitualidad intersubjetiva que se quiebra, por ejemplo, cuando nos vamos de viaje y visitamos una cultura diferente a la propia o cuando -importante para nuestra discusión- leemos una obra literaria que plantea un universo ajeno al nuestro.

Como bien lo ha expuesto Steinbock (1995), la constitución experiencial del mundo común intersubjetivo, de la experiencia de lo familiar y de lo propio-intersubjetivo, es el tejido geohistórico que sirve de trasfondo a nuestra vida consciente. Las prácticas sociales, los espacios habitados y vividos, las tradiciones, tejen una normalidad que nos sitúa como sujetos en un mundo intersubjetivo del que participamos, entre otras cosas, lingüísticamente. Nuestra experiencia del mundo social está definida por un proceso de sedimentación socio-histórico que da cierta densidad a nuestras tradiciones y que sitúa intersubjetivamente cada una de nuestras acciones incluyendo, por supuesto, aquellas relacionadas con el lenguaje. Cada acto interpretativo supone este trasfondo geohistórico intersubjetivo, y así interpretar una obra literaria no solo tendría que ver con la aprehensión de los significados lingüísticos, sino con la recreación del objeto narrado en función de las dinámicas propias de nuestra situación geohistórica. Así, mientras que el lenguaje dirige la atención a los elementos nominalmente definidos por las expresiones

6 Aunque esta idea de los puntos ciegos está ya en la obra de Ingarden (1998), el tratamiento que hago aquí es diferente porque lo abordo desde la fenomenología generativa. 
lingüísticas, hay una zona de indeterminación que el lector completa de la mano de lo que en la configuración de su mundo intersubjetivo sería lo normal.

En suma, la interpretación de una obra literaria despendería de la relación de al menos tres dimensiones:

a. La organización formal y estructural de la materia fónica.

b. La organización de los significados que presentifican el objeto intencional de una manera determinada.

c. El trasfondo geohistórico que sirve de telón de fondo a todo acto interpretativo.

\section{LA PINTURA Y LOS SIGNOS VISUALES}

Siguiendo los lineamientos expuestos en 2.1., en tanto que es un signo, una imagen visual es una apercepción en la que el objeto temático es el ítem ausente: presentifica, esto es, hace presente un objeto a la consciencia, por medio de un signo que le sirve de sustituto. Sin embargo, en el caso de las imágenes el rasgo distintivo es que la presentificación está relacionada con un acto de percepción en la que el objeto representado comparte algunas cualidades sensibles con la imagen propiamente dicha. Para Husserl, el acto intencional en el que la conciencia se dirige a su objeto mediante una imagen consta de tres elementos: la imagen-cosa, el objeto-imagen y el tema de la imagen (Husserl, 2005: 21). Por ejemplo, cuando vemos La noche estrellada de Van Gogh, tenemos en primer lugar la imagen-cosa: un objeto con un tamaño específico de forma rectangular que se puede colgar de la pared, se puede romper, alzar, transportar, etc. En tanto que objeto-imagen, el cuadro consta de una serie de colores y de formas que representan el tema de la imagen, esto es, el objeto representado: cuando observo una pintura, veo el objeto-imagen, pero mi acto se dirige al tema de la imagen. Si pongo un poco de pintura verde sobre el lienzo, estaría cambiando el objeto-imagen, pero no -es claro- el tema, es decir, las montañas y el cielo que la pintura representa. Desarrollemos un poco más esta distinción.

En primer lugar, el objeto-imagen es el soporte de las cualidades sensibles visuales que permiten acceder al tema de la imagen. Cuando hablamos de la materia sensible de los signos lingüísticos sugerí que su organización se establecía de la mano de la síntesis temporal. En el caso de la imagen, aunque toda experiencia consciente es siempre una experiencia extendida en el tiempo, las cualidades visuales se organizan, además, espacialmente. En este caso las operaciones de síntesis (homogeneidad y heterogeneidad) se mantienen, sólo que relacionadas con cualidades visuales extendidas en el espacio, como muestran muchas de las reglas de organización de la información 
visual formuladas por la Psicología de la Gestalt. Los signos visuales se ven como un todo en el que las partes se organizan según una sintaxis tabular (Groupe $\mu, 1993$ ).

En segundo lugar, la similaridad que funda la relación entre el objeto-imagen y el tema de la imagen admite grados: una cosa puede ser más o menos parecida a otra. La posición de Husserl no es muy distinta a la que defiende Groupe $\mu$ en el Tratado del signo visual (1993: 160): la semejanza entre el objeto-imagen y el tema de la imagen se puede especificar extensivamente, atendiendo al número de rasgos visuales que comparten entre sí, o intensivamente, atendiendo al modo de realización del rasgo. En una caricatura, por ejemplo, la cantidad de rasgos es limitada, pero los rasgos que componen el objeto-imagen tienen una intensidad tal que el reconocimiento del tema representado es inmediato; en un dibujo hecho con lápiz por un buen dibujante, el objeto-imagen realizará más rasgos visuales del tema que los que se realizan en una caricatura, pero se dejará de lado, por ejemplo, lo relacionado con el color. De igual manera, en una pintura hiperrealista, que es el tipo de pinturas de las que trata el cuento de Cortázar, el objetoimagen realiza los rasgos del tema tanto intensiva como extensivamente.

En tercer lugar, tal como lo ha planteado Sonesson (2015), en el caso de las imágenes visuales las formas y los colores no sólo configuran unidades de rango superior, como sucede en el caso de la lengua con los fonemas y las palabras, sino que una misma unidad cambia de estatuto dependiendo de su lugar en el objeto-imagen: un punto hace parte de la totalidad de la cara, y solo en ese contexto pictórico específico se entiende como un ojo, algo que no pasa con los fonemas que nunca llegan a ser-diríamos en la terminología estructuralista- unidades significativas.

En cuarto lugar, también con Sonesson (2015), una imagen visual se diferencia de los signos lingüísticos en tanto que el objeto-imagen guarda una relación de mediación visual con el objeto, y no una de mediación conceptual como la que vimos se daba en el caso de los signos lingüísticos. La diferencia entre expresión, contenido conceptual y objeto intencional no funciona para el caso de las imágenes, pues el acto interpretativo, aunque comparte la estructura general del signo enunciada en 2.1., es de una naturaleza particular: cuando vemos una fotografía, vemos de manera indirecta el tema de la imagen.

\section{ESCRITURA E IMAGEN EN FIN DE ETAPA}

Como dije al comienzo, al presente artículo lo animan dos objetivos diferentes relacionados entre sí: por una parte, entender, de la mano de la fenomenología husserliana y de su apropiación semiótica, las diferencias que hay entre texto e imagen, así como la relación que puede haber entre ambas dimensiones en la interpretación de un texto. Por el otro, hacer una aproximación al cuento Fin de etapa, de Julio Cortázar, para comprender el giro que el cuento propone en relación con la pintura. 


\subsection{EL CUENTO}

Ya he adelantado algo sobre el cuento. Se trata de una mujer, Diana, quien en medio de un trayecto no sabemos hacia dónde, decide tomar un descanso y se detiene en un pueblo dominado por una tranquilidad y una quietud que contrasta con la agitada vida de la que parece huir Diana. En el pueblo hay un museo que exhibe una exposición de unos cuadros que sobresalen por su grado de semejanza con el objeto representado, al punto que en un principio Diana cree que se trata de fotografías. Al llegar a la última sala del museo, Diana no alcanza a ver el último cuadro de la exposición y decide salir a almorzar y volver más tarde a terminar su visita. En el recorrido por el pueblo encuentra una casa a la que entra, luego de constatar que su interior parece ser el otro lado de los lienzos que había en el museo:

El jardín un poco abandonado no tenía árboles, dejaba que los ojos corrieran libremente hasta la ancha puerta abierta de la vieja casa. Sin creerlo y a la vez sin negarlo Diana entrevió en la penumbra una galería idéntica a la de uno de los cuadros del museo, se sintió como abordando el cuadro desde el otro lado, fuera de la casa en vez de estar incluida como espectadora en sus estancias (Cortázar, 1996: 427).

Una vez recorre la casa, Diana abandona el pueblo, pero perseguida por unos interrogantes que la empujan desde el pasado y que son en última instancia los embates de su relación fallida con Orlando, decide volver a ver el último cuadro, uno que no pudo ver en su primera visita al museo. Al llegar, observa el retrato de una mujer sentada en una silla:

El brazo izquierdo colgando a lo largo del cuerpo, la leve inclinación del torso que descargaba su peso sobre el codo invisible apoyado en la mesa, estaban diciéndole otra cosa a Diana, le estaban mostrando un abandono que iba más allá del ensimismamiento o la modorra. Esa mujer estaba muerta, su pelo y su brazo colgando, su inmovilidad inexplicablemente más intensa que la fijación de las cosas y los seres en los otros cuadros: la muerte ahí como una culminación del silencio, de la soledad de la casa y sus personajes, de cada una de las mesas y las sombras y las galerías (Cortázar, 1996: 431).

Lo que sigue es la resolución literaria de lo que sería una especie de oxímoron narrativo que tiene como punto final la escena de cierra del cuento, en la que Diana se vuelve un objeto más en una de las pinturas. Los cuadros del museo, que impactan por su realismo, representan un mundo que en principio se asume como irreal. Pero la casa, que es real, genera en Diana una sensación de extrañeza que recubre todo de un manto de irrealidad manifiesto. La mujer que aparece en la pintura vive, pero está muerta 


\section{CARLOS ANDRÉS PÉREZ RAMÍREZ}

porque es un reflejo de Diana, muerta en vida, para quien la existencia no es otra cosa que un viaje sin sentido: "curioso que la vida pueda volverse una simple aceptación" dice Diana al inicio del cuento, "incluso esta aceptación de no aceptar nada, de irme casi antes de llegar, de matar todo lo que todavía no es capaz de matarme" (Cortázar, 1996: 426). Es la mujer del cuadro la que vive, inmersa en esa quietud en la que la vida se convierte en un solo presente contemplativo. Es esa mujer la que vive y no Diana, cuya vida se ha perdido ya en medio de los acontecimientos sin importancia. Por eso el cuento termina cuando Diana decide volver a la casa y sentarse en el banco, encarnando la mujer muerta retratada en la última pintura del museo, contemplando el humo del cigarrillo, aceptando su condición humana y, por eso mismo, más viva que nunca:

Podía irse cuando quisiera, por supuesto, y también podía quedarse; acaso sería hermoso ver si la luz del sol iba subiendo por la pared, alargando más y más la sombra de su cuerpo, de la mesa y de la silla, o si seguiría así sin cambiar nada, la luz inmóvil como todo el resto, como ella y como el humo inmóviles (Cortázar, 1996: 432 y 433).

\subsection{LAS PINTURAS Y EL RELATO}

El giro que propone Cortázar al situar a Diana como personaje de las pinturas, y la intensa y brillante solución que plantea al final del cuento, le dan al relato un peso literario extraordinario. Sin embargo, cuando se tiene acceso a las pinturas que motivan el cuento, lo narrado se particulariza y se especifica al punto que su sentido se expande en una dimensión intertextual que hace de su interpretación una experiencia completamente diferente. En lo que sigue voy a analizar este cruce de la mano de las ideas expuestas en los numerales 2 y 3 , para dar cuenta del doble papel que juegan las pinturas en la apropiación literaria que de ellas hace Cortázar en el cuento.

\subsubsection{El objeto-imagen en el relato}

En la primera parte del cuento encontramos una serie de descripciones lingüísticas de los cuadros. Según lo dicho en 2.2., las descripciones son solamente conceptualizaciones que presentifican el objeto de manera parcial, en este caso las pinturas, pero el acto interpretativo supone un trasfondo que se configura a partir de un mundo compartido normalizado (un hogar, dijimos) que en este caso sería el de las tradiciones artísticas y los modos de representación pictórica y de representación visual. No obstante, lo que en principio es solo un acto significativo, se enriquece sensiblemente cuando se observan las pinturas que inspiraron el cuento. Se trata de una serie de cuadros realizados por 
Antoni Taulé -a quien Cortázar (1996: 426) dedica el cuento "por ciertas mesas"- algunos años antes de la publicación del volumen de cuentos titulado Deshoras, en el que se encuentra Fin de Etapa. Las imágenes 1 y 2 presentan un par de ejemplos de algunas de las obras que satisfacen la descripción dada en el cuento.

En esta primera parte del cuento, las descripciones corresponden al objeto-imagen: se describe, efectivamente, lo que está dibujado, esto es, el cuadro como tal. Y ver las pinturas está cerca de lo que Husserl (1999: 605) llama en las Investigaciones lógicas una síntesis de cumplimiento, esto es, la presentación intuitiva de lo que lingüísticamente era solo una apresentación mediada por un contenido conceptual. Es claro que en no estamos frente a las pinturas reales, y que hay unas diferencias cualitativas notorias entre la reproducción que encontramos en la página web y los cuadros originales. De todas maneras, para mantener la oposición que me interesa, diré que entre la descripción lingüística y la reproducción visual de las pinturas hay una síntesis de cumplimiento parcial en la medida en que las pinturas efectivamente cargan de contenido sensible lo que hasta el momento era solo una intención significativa.

Según vimos, hay dos tipos diferentes de actos intencionales: intenciones vacías (de las que hablamos ya ampliamente, pues es el caso de las intenciones sígnicas) e intenciones cumplidas. En una intención vacía el objeto no está presente de manera directa; es el caso de un recuerdo o de una descripción lingüística. En los actos perceptuales, por el contrario, el objeto se da de manera directa, esto es, intuitivamente.

Tal es el caso cuando vemos las pinturas de Taulé, incluso si se trata de reproducciones digitales. En efecto, salvando lo dicho al inicio de este párrafo y retomando la idea final de 3, en el caso de las imágenes visuales, y más en el de las pinturas que nos ocupan, ver el objeto-imagen es también ver el objeto intencional de la descripción lingüística. En pocas palabras, el objeto de la descripción lingüística de las pinturas es el objeto-imagen, mientras que el objeto de las pinturas es, en el universo diegético del cuento, la casa a la que entra Diana luego de su paseo por el pueblo.

Volviendo sobre Husserl, el punto importante es que la experiencia perceptiva de un objeto vale como acto de cumplimiento solamente si da cumplimiento a una intención significativa. Cuando alguien dice "hay un elefante en la habitación de al lado", quien interpreta ese acto de habla lo hace mediante una intención significativa, y su mente se dirige a la situación definida por la expresión. Ahora bien, si quien escucha la frase es, además de buen entendedor, un espíritu curioso y no resiste las ganas de asomarse a ver el elefante, cuando lo observa le da cumplimiento, en el acto perceptivo, a la intención significativa. El cumplimiento es la experiencia de la coincidencia entre la intención vacía y el objeto presente. Y este es, precisamente, el caso de la experiencia de las pinturas de Taulé.

Si revisamos el repertorio de obras que realizó Taulé por la época del cuento, son muchas las que pueden darle cumplimiento intuitivo a las descripciones que hace 
Cortázar en el cuento. De hecho, en los ejemplos que aparecen en la Imagen 1 y la Imagen 2 (ver infra) escogí aquellas que se ajustaban mejor a la descripción, sin saber (y sin importar) si efectivamente fueron esas las que tenía en mente Cortázar al momento de escribir el cuento (esta sería una cuestión empírica que no resulta relevante para nuestra discusión). Si una pintura da o no cumplimiento a la descripción hecha por el cuento es algo que puede determinarse atendiendo al significado de la intención significativa. Y aquí resulta muy útil volver sobre las nociones de focalización y granularidad.

Sobre la granularidad, el asunto parece claro: el detalle de la descripción orienta, de manera más o menos decidida según sea el caso, el acto de cumplimiento. Si con respecto a las pinturas el cuento diera solamente una descripción gruesa, muchas de ellas podrían satisfacer la descripción dada por el relato, mientras que una descripción más fina reduciría el rango de posibilidades de cumplimiento. Al respecto, el cuento se ubica en una posición intermedia y opta, más bien, por introducir elementos distintivos en el marco de una descripción general de las pinturas: la mayoría de las pinturas presentan mesas, pero sólo algunas presentan un hombre, y de esas, hay sólo una que lo presenta dándole la espalda al espectador. Así, la descripción que hace Cortázar de las pinturas captura en un primer momento el rasgo general que las define en conjunto, el tema que las recorre y el estilo que las caracteriza, y sólo después pasa a dar detalles que las individualizan. Por eso la síntesis de cumplimiento no consiste, o no solamente, en hacer una relación puntual entre cada pintura y la presentación que de ella se hace en el cuento; antes bien, cuando tenemos acceso a los cuadros de Taulé habiendo leído con anterioridad el cuento, el cumplimiento se da en los términos propuestos por la narración. Cortázar establece una manera de ver las pinturas, resaltando algunos aspectos y dejando de lado otros, y el trabajo del intérprete es, entonces, parecido al de una persona que entra en una habitación con un martillo y detecta rápidamente los clavos sueltos. Es por eso que la síntesis de cumplimiento entre la narración y la captura directa de las pinturas no se debe entender dentro del marco de una teoría del conocimiento, que es lo que preocupa a Husserl en las Investigaciones Lógicas. Antes bien, además de darle un contenido sensible a lo que solo era una intención vacía, la contemplación de las pinturas va de la mano de una sanción afectiva.

Husserl trabajó intensamente, en los años posteriores a 1912, en el problema del papel del cuerpo y de la experiencia corporal en la constitución de nuestra experiencia del mundo, y advirtió cómo antes que una relación intelectual, cognoscitiva con el mundo, la situación del ser humano se organiza en función de la experiencia del cuerpo vivido (Husserl, 2001). Se trata de una experiencia cualitativamente definida en términos de sensaciones táctiles y kinestésicas que configuran el rango de posibilidades prácticas que Husserl denomina "yo-puedo". Si veo una silla al frente de mí puedo capturar la escena en un juicio del tipo "la silla es verde". No obstante, además de la posición intelectiva hay 
una dimensión más básica que se define en relación con las posibilidades motoras que mi cuerpo vivido admite en relación con la silla. Me puedo sentar, parar, la puedo rodear, etc. $Y$ este tipo de posibilidades prácticas están cargadas subjetivamente: si mi cuerpo se modifica, también lo hace mi horizonte práctico, no así con los actos judicativos, que expresarían un valor de verdad independientemente de las particularidades de mi cuerpo.

Ahora bien, en la medida en que nuestro cuerpo es el centro de nuestra experiencia, es claro que ésta está siempre teñida -por decirlo de alguna manera- afectivamente, pues la vivencia de nuestro cuerpo tiene de suyo un valor afectivo. Digo todo esto porque en el caso de la contemplación de las pinturas que Cortázar describe en el cuento, la síntesis de cumplimiento -la experiencia de la coincidencia- está acompañada de una carga afectiva que valida la relación: no solo sabemos que hay una correspondencia; también la vivimos. Y esta vivencia está determinada por el modo específico en que el Cortázar describe la visita de Diana al museo.

Vamos ahora al asunto de la focalización. En el cuento, la descripción de las pinturas tiene lugar en dos párrafos diferentes. En primero, Cortázar focaliza los cuadros y se centra en las características de las pinturas:

En la primera sala había cuatro o cinco pinturas que volvían sobre el tema de una mesa desnuda o con un mínimo de objetos, violentamente iluminada por una luz solar rasante. En algunas telas se sumaba una silla, en otras la mesa no tenía otra compañía que su sombra alargada en el piso azotado por la luz lateral (Cortázar, 1996: 431).

Cortázar termina este párrafo dándole voz a Diana, en un cambio en la focalización que abre la puerta al segundo párrafo en el que la descripción se centra en la manera como Diana vive las pinturas:

Las miraba, por supuesto, pero un poco como si no las viera, la secuencia de la casa con las mesas solitarias tenía tanta fuerza que el resto de las pinturas se convertía en un aderezo suplementario, casi como si fueran cuadros de adorno colgando en las paredes de la casa pintada y no en el museo. Le hizo gracia descubrirse tan hipnotizable, sentir el placer un poco amodorrado de ceder a la imaginación, a los fáciles demonios del calor de mediodía (Cortázar, 1996: 431).

El cambio de focalización deja ver que la síntesis de cumplimiento descansa en la información que el cuento presenta en el primer párrafo. Si la narración estuviera completamente volcada hacia la situación de la protagonista, la relación con las pinturas 
se desvanecería. Sólo cuando el foco temático se desplaza hacia el lado objetivo puede haber cumplimiento significativo; no así cuando se desplaza hacia el lado subjetivo. Cuando leemos que Diana miraba las pinturas como si no las viera, esa experiencia escapa a cualquier acto de cumplimiento: en estricto sentido, no podemos tener la experiencia de Diana en carne propia. Podemos, a lo sumo, ponernos en sus zapatos, pero esto no es lo mismo que tener su experiencia. El Otro es siempre inalcanzable; una subjetividad que encara al mundo desde un horizonte experiencial que es de suyo diferente al propio. Y el trabajo -trágico- del escritor consistiría precisamente en atreverse a recorrer ese abismo, aunque el trabajo esté destinado al fracaso. $Y$ de esto es de lo que se trata el giro fantástico que da el cuento al final.

\subsubsection{El tema de la imagen en el relato}

El asunto que nos ocupa es el de la manera como el acceso directo a las pinturas de Taulé se da la mano con la lectura, en el proceso de construcción de sentido relacionado con el cuento. Así, he tratado, simplemente, desarrollar y especificar, de la mano de las ideas de Husserl, la idea básica según la cual uno es el proceso interpretativo si no se conocen las pinturas que dieron lugar al cuento, y otro cuando se ven. En este apartado me centraré en la manera como el acceso a las pinturas afecta la interpretación del giro fantástico que tiene lugar hacia el final del relato, cuando Diana termina volviéndose la mujer retratada en el último de los cuadros que hay en la galería. Y lo voy a hacer tratando de ir más allá de la que creo sería una posición simple: la de limitarse a señalar que con respecto a la casa que recorre Diana hay una captura doble, una verbal y una visual, y que entre las dos se da una posición de relevo del tipo propuesto por Barthes en su clásico Retórica de la imagen (Barthes, 1986)

En primer lugar, es importante anotar que la construcción gramatical puede ser la misma -o casi la misma- cuando se habla de los cuadros que cuando se habla de la casa. Lo que cambia es el objeto intencional: en la primera mitad del cuento Cortázar habla de las pinturas; en la segunda de las habitaciones de la casa. En la terminología de la lingüística cognitiva, se trataría de una misma frase que organiza dos espacios mentales diferentes, uno referido a los cuadros del museo, otro referido a la casa. No es ese el caso de las pinturas, pues el objeto-imagen representa el tema de la imagen, que es siempre la casa. Sin embargo, en el caso de las pinturas el acceso al tema de la imagen es más directo, en tanto que no está mediado por una construcción conceptual sino por una mediación visual. Así, las pinturas limitarían el modo de presentación lingüístico en el ejercicio de imaginar a Diana recorriendo los espacios de la casa, y en ese orden de ideas podemos tener una captura más clara de su situación. 
En segundo lugar, el relevo es, en realidad, un contrapunteo entre lo visual y lo conceptual en cuanto al modo de presentación. Así, no se trata simplemente de acercar al espectador a la situación representada; se trata también de distanciarlo, pero hacerlo dentro de las reglas que rigen la interpretación de los signos visuales. Como ya dije, lo lingüístico solamente puede organizar conceptualmente una escena, y es en función de las posibilidades gramaticales y conceptuales de las que dispone el usuario de una lengua que la escena se presentifica, aunque sea de manera vacía. Por el contrario, el marco intencional propio de una obra de arte se establece a partir de la percepción de ciertas propiedades visuales (formas, colores, texturas)7 del objeto-imagen. Y en el caso de la pintura, como lo ha señalado Bundgaard (2015), el rasgo distintivo de la experiencia estética tiene que ver con la postulación, por parte del espectador, de la intención de configurar voluntariamente una superficie visual por parte del artista. En los términos trabajados en el presente artículo, cuando percibimos una obra de arte somos capaces de reconocer la manipulación que del objeto-imagen hace el artista, y capturamos la manera como las relaciones entre los colores o la composición formal de una pintura (por ejemplo, la organización triangular de los cuerpos en Santa Ana, la Virgen y el Niño de Da Vinci) se imponen sobre el tema de la imagen representado. Eso es lo que diferencia la percepción directa de una escena, de la percepción de las pinturas que la representan. Y sería, también, lo que diferenciaría una fotografía ordinaria de una pintura.

Lo interesante de las pinturas de Taulé es que intentan difuminar esa frontera con el tema de la imagen, pero al hacerlo la afirman de manera mucho más radical. Cuando Diana entra en la galería Cortázar describe las pinturas así:

En el primer momento pensó que eran fotografías y le llamó la atención el tamaño, poco frecuente ver ampliaciones tan grandes a color. Se interesó de veras cuando recordó la materia, la perfección maniática del detalle; de golpe fue a la inversa, una impresión de estar viendo cuadros basados en fotografías, algo que iba y venía entre los dos (Cortázar, 1992: 427).

Solo una mirada cuidadosa advierte que se trata de pinturas y no de fotografías, borrando en principio la frontera entre lo esencialmente pictórico y la simple reproducción visual de una escena. Se trata de construcciones visuales en las que se trata de vincular el tema con el objeto tanto extensiva como intensivamente, en el sentido expuesto en 3. Sin embargo, el peso estético de la propuesta de Taulé radica en que ese cuidadoso realismo va de la mano de una cuidadosa manipulación tanto del color como de la disposición espacial de las figuras que componen el objeto-imagen. Para ponerlo

7 Sigo en esto, de nuevo, las ideas de Groupe $\mu$ (1993). 
en pocas palabras, el esfuerzo por reproducir de la manera más fiel posible el tema de la imagen tiene un efecto contrario: resalta el trabajo artístico que hay detrás de su producción. En las pinturas se advierte una constante oposición entre la luz amarilla y la sombra, los objetos representados desaparecen en la sombra sin un límite definido y se presenta repetidamente la fusión de lo que sabemos son dos objetos diferentes. En pocas palabras, el realismo que se logra con la capacidad técnica del artista se contrapone a su genio estético, esto es, a la manera como concibe y presenta cada una de las escenas.

Solo por eso, por las cualidades estéticas, es que la inmersión de Diana en la casa adquiere el tono que adquiere, y eso es lo que rescata y presenta de manera notable Cortázar en su relato. Diana no está, simplemente, ingresando a una casa: está ingresando a un espacio dominado por las cualidades estéticas que caracterizan las pinturas de Taulé, y de eso es precisamente de lo que se trata el giro fantástico propuesto por el relato. Lo que logra Taulé, la distancia de lo real por medio del realismo excesivo, lo recorre Cortázar caminando en la dirección contraria: al final del cuento el tema de la imagen se funde con el objeto-imagen; las cualidades estéticas se vuelven entonces cualidades del tema de la imagen, y a Diana no le queda más que clausurar la temporalidad mundana de su existencia en la inmovilidad del objeto-imagen.

\section{ANEXO}

\section{Imagen 1}

En la primera sala había cuatro o cinco pinturas que volvía sobre el tema de una mesa desnuda o un mínimo de objetos, violentamente iluminada por una luz solar rasante (Cortázar, 1996: 428).

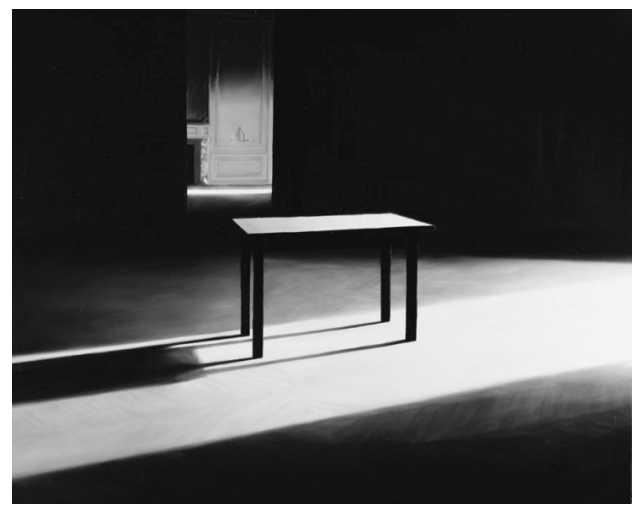

Antoni Taulé, 1979. Réalité et irrealté.

http://www.antonitaule.com/paintings/realite-et-irrealite/ [19/05/2016].

Reproducido con autorización del autor. 
SOBRE LA RELACIÓN ENTRE TEXTO E IMAGEN. UNA APROXIMACIÓN SEMIOFENOMENOLÓGICA A FIN DE ETAPA, DE JULIO CORTÁZAR

\section{Imagen 2}

Cuando entró en la segunda sala vio algo nuevo, una figura humana que tenía un interior con una amplia salida a jardines poco precisos. La figura, de espaldas, se había alejado ya de la casa donde la mesa inevitable se repetía en primer plano (Cortázar, 1996:426)

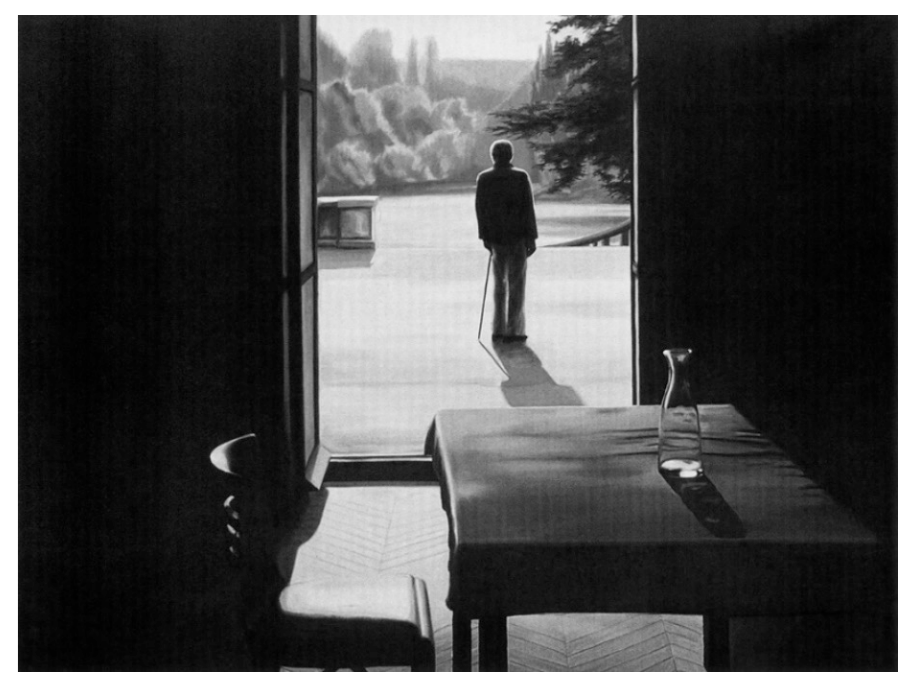

Antoni Taulé, 1978. Témoignage.

http://www.antonitaule.com/paintings/temoignage/[19/05/2016].

Reproducido con autorización del autor. 


\section{REFERENCIAS BIBLIOGRÁFICAS}

ALAZRAKI, J. (1994). Hacia Cortázar. Aproximaciones a su obra. Barcelona: Anthropos.

BARTHES, R. (1986). “Retórica de la imagen". En Lo Obvio y lo Obtuso. Barcelona: Paidós, pp. 2948. (2009). La aventura semiológica. Barcelona: Paidós.

BERGEN, B. (2012). Louder than Words. New York: Basic Books.

BRANDT, L. (2013). The Communicative Mind. New Castle: Cambridge Scholar Publishing.

BRANDT, P. A. (2004). Spaces, Domains and Meanings. Berna: Peter Lang.

BUNDGAARD, P. (2010). "Means of meaning making in literary art: focalization, mode of narration and granularity". Acta linguistica hafniensia. International journal of linguistics 42. $1,64-84$

(2015). "Feeling, Meaning and Intentionality". Phenomenology and the Cognitive Sciences $14.4,781-801$.

CLARK, H. (1996). Using Language. Cambridge: Cambridge UP. CORTÁZAR, J. (1996). "Fin de Etapa”. En Cuentos completos / 2, 426-433, Madrid: Alfaguara.

ECO, U. (2005). Tratado de Semiótica general. Barcelona: Lumen.

FLOCH, J.-M. (1993). Semiótica, Maketing y Comunicación. Bajo los Signos, las Estrategias. Barcelona: Paidós.

GROUPE $\mu$ (1993). Tratado del Signo Visual. Madrid: Cátedra.

HAGHROOSTA, M. (2011). “Una lectura de Fin de Etapa. La configuración de los espacios como detonante de los fantástico". Hisperia. Anuario de Filología Hispánica XV.1, 29-46.

HUSSERL, E. (1999). Investigaciones lógicas, vol. 2. Madrid: Alianza Editorial. (2001). Analyses Concerning Passive and Active Synthesis. Dordrecht: Springer. (2005). Phantasy, Image Consciousness and Memory (1898-1925). Dordrecht: Springer. (2009). Lógica formal y Lógica trascendental. México D. F.: UNAM.

INGARDEN, R. (1998). La obra de arte literaria. México D. F.: Taurus.

KLINKENBERG, J.-M. (2006). Manual de Semiótica general. Bogotá: Universidad Jorge Tadeo Lozano.

LANGACKER, R. (2008). Cognitive Linguistics. An introduction. New York: Oxford UP.

PÉREZ, C. (2016). "The mutual enlightenment. A phenomenological interpretation of the embodied simulation hypothesis". En Meaning, mind and communication: Explorations in cognitive semiotics, J. Zlatev, G. Sonesson, \& P. Konderak (eds.), Frankfurt am Main: Peter Lang.

PREGO, O. (1997). La fascinación de las palabras. Buenos Aires: Alfaguara.

RUIZ, C. (1996). “Fin de etapa”. Revista Chilena de Literatura 48 (abril), 113-119.

SONESSON, G. (2012). "The Foundation of Cognitive Semiotics in the Phenomenology of Signs and Meanings". Intellectica 58.2, 207-239. 
SOBRE LA RELACIÓN ENTRE TEXTO E IMAGEN. UNA APROXIMACIÓN SEMIO-

\section{FENOMENOLÓGICA A FIN DE ETAPA, DE JULIO CORTÁZAR}

(2015). "The Mirror In-Between Picture and Mind. A Phenomenological Inspired Approach to Cognitive Semiotics". Chinese Semiotic Studies 11.2, 159-180.

STJERNFELD, F. (2014). Natural Propositions. Boston: Docent Press.

STEINBOCK, A. (1995). Home and Beyond. Generative Phenomenology after Husserl. Evanston:

Northwestern UP.

TALMY, L. (2003). Toward a Cognitive Semantics. New York: Bradford Books.

ZLATEV, J. (2010). “Phenomenology and Cognitive Linguistics”. En Handbook of Phenomenology and Cognitive Sciences, D. Schmicking y S. Gallagher (eds.), 415-443. Amsterdam: Springer.

Recibido el 28 de mayo de 2016.

Aceptado el 15 de noviembre de 2016. 
